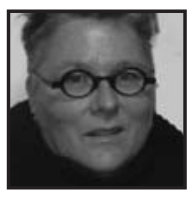

\title{
(En)Gendering Difference: A For(u)m for Possibilities
}

\section{Pam Patterson, Ontario Institute for Studies in Education, Centre for Women's Studies}

\section{ABSTRACT}

This inquiry observes how cultural collaborations can create for(u)ms-forms representing narrative activity; for-"ums" for reflective pauses; and forums for discussionto critically address and provide spaces for playing in and with differences in ability, race, gender, and ethnicity. Using the project gender/TROUBLING as template, it theorizes a performative model for learning to explore the possibilities for engendering diversity and for building responsive, creative, and inclusive teaching/learning practices.

\begin{abstract}
Discovery consists of looking at the same thing as everyone else does and thinking something different.
\end{abstract}

Albert Szent-Gyorgyi (date unknown)

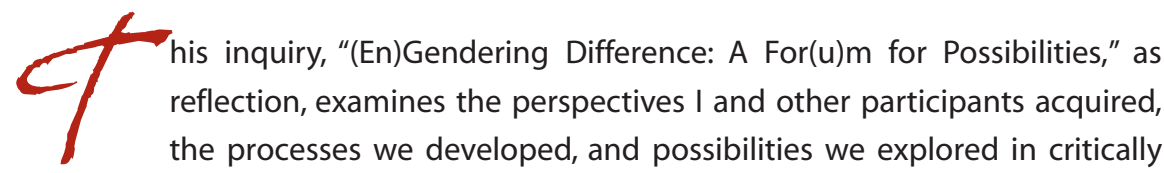
addressing and providing a space for playing with, and negotiating through, differences in ability, gender, ethnicity, and culture through our engagement in a particular arts collaboration and event. As research, it reflects on how such collaborations, actively pausing and playing, can frame a processual learning for $(\mathrm{u}) \mathrm{m}$ for participants. Here for $(\mathrm{u}) \mathrm{m}$ is used to mark complexity and multiple processes in arts learning: as form made by artist and then used by onlookers in/for interpretation; for "um," 
the pauses (often reflective) in activity (Patterson, 2006); and the forum, as an active and acknowledged site for discussion and knowledge making. My intention in fragmenting this word is to disrupt reader preconceptions and assumptions, open theoretical spaces for new configurations of difference and to name, as author, an active site for the performance of meaning.

I focus this discussion around gender/TROUBLING, a creative program I initiated as Director of WIAprojects, a feminist interdisciplinary educational, exhibition, performance, and arts-informed research program housed at the Centre for Women's Studies in Education, Ontario Institute for Studies in Education of the University of Toronto.

gender/TROUBLING was both the title for the project and for the resulting exhibition, performance, film screening, and discussions that were held at XPACE Cultural Center, Toronto. Participants were from WIAprojects, XPACE, York University, the Ontario College of Art and Design University, the Art Gallery of Ontario Youth Council, and other community curators and artists.

My own creative work, as autobiographical, stories a woman gendered as older, queer, and disabled. Often my installations and performances are ghettoized in queer, women's or disabled exhibitions, or if shown or performed in mainstream galleries, bodily appearance and sexuality are downplayed or sometimes exoticized by viewers and interpreters. Stories of similar troubling or reductive experiences by various cultural workers were sent to me via mail or email, through blog posts, or told to me in person. These individuals were invited to join the project and if time and personal commitments allowed, they became active participants. What we had in common was that each of us had been asked at one time or another to simplify our complex autobiographies and define ourselves and our work into one category for exhibition and discussion. Gender definition was limited to straight, gay or maybe queer; and rarely were the complexities of race, class, ability or age, for example, included with/in gender. Many times we were asked to make work or to speak publicly in such a way that did not acknowledge our complex gendered selves at all.

Our intention was to explore how we could collaborate and produce work that could represent and perform these complexities. 


\section{Revealing Perspective and Initiating Process Through Story}

The stories we told each other or shared through writing went beyond simply naming exhibition frustrations. Personal and schooling experiences also were articulated. Many of these stories served in analysis as open forms, as musings. I choose the word "muse" intentionally to note a rich resonance that comes from attending to individual presence in story. Stories can provide opportunities for conversations and connection, and stimulate personal insight. They can offer a beginning place for an exploration of the process of self-identity and sometimes better reveal the complexities of gender. As others, such as the Personal Narratives Group (1989), have commented, such a venture will probably not settle the argument concerning the location of the self: whether it is there to be discovered (or uncovered) and relatively stable, or whether it is a construction of the mind and continually shifting. However it will provide an entry point for examining the interaction between the individual and society in the construction of gender. If we understand each of our stories as a recording of our gender status, then gender will never be taken for granted and our stories will become evidence of historical activity that illuminates both the effects of systemic constraints and the potential impact of individual agency. These narratives can allow us to see our lives as simultaneously individual and social creations, and to see ourselves as individuals who are simultaneously the changers and the changed.

gender/TROUBLING stories were counter-narratives and spoke to the power of individual agency and to the understanding that participants had of collective interdisciplinary work. The project took place in a gallery space, which while funded by an educational institution, was not so policed. Participants also came from many different sites-institutional and non-institutional—which also served to destabilize a fixed discourse. The project developed from a shared passion for gender difference and fluidity, for powerful stories, and from our desire to understand and interpret such "stories of difference" for ourselves and for others.

From our early meetings questions emerged:

What are the challenges we have within our communities? How do we, and those we work with, understand "gender"? How limiting can that term be?

How might we unpack it?

What are some of the strategies that we could use, as educators, curators, and artists, 
to create spaces to celebrate, activate, and engage our diverse community(ies)? How can we rethink what we do as pedagogy and use it to animate action?

We explored how to aesthetically activate and integrate complex gender issues in exhibition. The description of "how" this occurred articulated the project's learning. Project learning was multilayered. Foregrounded here in this writing are the understandings I reached around my own facilitation of, and curatorial strategies used for responding to, and developing and animating, project questions. It also includes, in part, participants' learning around how story could build performance and new media representations, how they might integrate and make use of reinterpretations of their work, and how they might animate, inform and respond to viewers' readings. It also discusses the learnings acquired by our viewers and discussion participants. In many instances these roles-as did our gender designations-overlapped and become fluid: the curator worked as an installation artist; artists became interpreters; and visitors assisted in facilitation. Learning was both individual and collective, a complex enactment and engagement. In reporting on this, while I include others' viewpoints, my writing is biased as I speak about how I viewed and interpreted project learning.

\section{Engaging Possibilities in "Play"}

gender/TROUBLING

Gender bend, gender blend-Oh ! Have we got trouble! The fun, sexxy, hot, meets "voguing" —What a "drag"! Get rid of those binaries! Engage with lifesized on the wall grls/gys and video and film by native-tranny-poly-queergimp-homo-gender-b(I)enders. "Perform” (or critique) a new persona at the gallery site, see a performance and a portable gender-abled potty, and workshop, in conversation, with the artists on site. Play with where you stand (or pass?)... anything is dizzyingly possible.

This was the exhibition invitation text as written by our collective. The language was intentionally chosen to provoke discussion and to defuse the power derogatory words can have when hurled against us.

gender/TROUBLING was a presentation-in-process. Our research drew from Judith Butler's (1988) early work on performative acts and gender constitution. Butler does not consider the performance of gender, sex, and sexuality to be a voluntary 
choice. She locates the construction of the gendered, sexed, desiring subject within what she calls "regulative discourses." These discourses, also called "disciplinary regimes," decide in advance the socially permitted possibilities of sex, gender, and sexuality. The discourse itself naturalizes the construction of binary gender and heterosexuality -in other words heterosexuality in the West appears "natural."

She writes,

Gender reality is performative which means, quite simply, that it is real only to the extent that it is performed. It seems fair to say that certain kinds of acts are usually interpreted as expressive of an expected gender core or identity, and that these acts either conform to an expected gender identity or contest that expectation in some way. $(1988$, p. 527)

Butler claims that, without an adequate critique of sex/gender, race, ability, age, etcetera, subversive performances will be seen as nothing more than futile acts.

In summarizing how such a critique might be activated, performance scholar and practitioner Richard Schechner (2006) writes, in referencing various theories of performativity, that a performance "act" has three branches-it has its physical attributes (to "do"), its social aspects (to "act"), and its theatrical aspects (to "perform"). "Any action consciously performed refers to itself. Its 'origin' is its repetition. Every consciously performed action is an instance of restored behavior. Restored behavior enacted in real life is what poststructuralists [such as Butler] call a performative.... all social identities are performatives" (p. 167). Of interest here in Schechner's argument is the relationship between performativity, the performative, and the performance proper: an "act" accomplished in everyday life becomes connected with "to act" something enacted for the stage-as art. When one is reflexive about one's acting, one becomes conscious of how such acting is constructed.

There is an "as if" of performativity analogous to the "as if" of theater. In theater, the "as ifs" consist of characters, places, actions, and narratives - all of which exist as they are performed. In performativity, the "as ifs" consist of constructed social realities - gender, race... - all of which are provisional. (p. 168)

While theatrical approaches dispense "information to spectators through closed narrative conventions" (Garoian, 1999, p. 49), those which employ performance do so through intervention. It invites a different way of perceiving. If a differently 
gendered, raced, disabled etcetera performative can be re-imagined "as if" and re-created in a "live" setting or formalized as a performance, might we perhaps raise the possibility that it might be "real" after all? Schechner notes, "It is possible... to progress from pretending to acting to performing to simulating... Phenomenologically, the distinction between real and feigned" might then potentially disappear (2006, p. 134).

Our intention, as an activist/artist collective, was to engage with this discussion as we built, contextualized, and presented our work. Our desire was to expand the field bodily through creatively constructed subversive performances of various kinds. Our strategy was one of play.

Maria Lugones (1990) notes,

The shift from being one person to being another person is what I call travel... Those of us who are "world" travelers have the distinct experience of being different in different "worlds"... The attitude that carries us through is [a] playful [one]... We are not worried about competence. We are not wedded to a particular way of doing things. We are there creatively. (p. 396)

We worked towards opening a for $(\mathrm{u}) \mathrm{m}$ where new meanings could assemble and shift, creating fluid narratives of change, using a construction which acknowledged the power of diverse art practices, the embedding of memory and story in image, and the productive use of fantasy. As artists, curators, and writers, we were implicated in the production of the interpretation enacted by the visual frame. Our production was transparent - the context and content evident in location, producer, place, and intent, enacted in discussion, and marked in publication. We strategically played together among our worlds, and in doing so, refused to stabilize gender.

How? We told and shared our stories and made these stories content for our art. As artists and researchers, we acknowledged our shared and different conditions and explored the complex interpretive practices that were at play. We admitted our complicity, and modeled and critiqued the roles we played in mediating, betraying, and building alliances among our diverse selves and communities. Rather than presenting easily recognizable images of the gendered body, we searched for ways to connect differently with our viewers. In engaging in such practices, we attempted in our art to be inextricably (and publicly) engaged in the conditions, context, positionality, and performativity of our gendered lives. 
Some artists came to the project with completed work from other contexts and used our for $(\mathrm{u}) \mathrm{m}$ to share their stories and recontextualize their work; some used feedback from weekly meetings and story sharing to go back into the studio and build their work; some brought raw footage to me and the group and we assisted in choosing which work to show and made suggestions on how best to show it. The final decision as to what to show or how it was to be shown was mine, but negotiation was critical. All were able to identify and realize their own work in relationship to the project intention and the exhibit as it was conceptualized.

\section{Curation as Pedagogy}

All of the works the artists developed addressed, in various ways, Butler's notion of performativity through the use of photo-based images, video, new media, performance, and sculpture. My intention, as curator, was to design an installation with the group that would articulate our collective work together in forms which would enact a more inclusive and complex performance of gender. I wanted viewers to become aware of, and perceive differently, gender variability and to understand the unique subjectivity of each artist and the particularity of each artist's story.

While I could understand how performance might activate the gendered body in space, I questioned how photo-image and sculpture might work. This hesitation influenced my choice to approach artists who mostly worked with less static forms-moving images, video and performance. However, regardless of whether the completed works were to be static or moving, live-sized or referencing the body as sculpture, I needed to look at how others could imagine themselves in the stories and move through the exhibition.

Cultural theorist Herta Wolff (2007) provided some context for affirming the potential of a static image to replicate performance intent for the viewer:

[I]n a photograph, what is viewed through and replicated by the lens is not only represented but also made present again.... This notion of photograph as a self-imprint of nature and the world endows each photograph regardless of the theoretical grounding of its viewer with an eminent link to the subjective, to experience. (p.69) 
While as an interpretive educator, I do not doubt an image's connection to experience, I am interested in how we can best predict certain viewings as researchers/ artists when we use different media to "perform" our own and other's experiences.

Through a performative reflexive inquiry-reflection within the context of the social and political for action-I facilitated discussions with the group on how their representations might work as explications of race, culture, disability, as well as of pain, confusion, and joy. How might this provide a learning experience and affect change for me, as curator/researcher, for them as artists/participants, and for our viewers? I then noted how each of these groups facilitated with varying results, these shifts in learning through a complex balancing and "performing" of various factors: research data, personal experience, aesthetics, art making process, and viewing practices.

Performance has been framed as pedagogy (Garoian, 1999) and used specifically to expose and address, for example, medical, disability, and race and gender challenges (Gray et al., 2000; Kuppers, 2003, 2007; Paget, 1990; Piper, 1996). Performance proposes that both artists and viewers become aware of the layering of action and image. It asks for a direct involvement of spectator with performer, transforming the role of spectator to one of participant (Garoian, 1999). As a form which is interventionist, it is useful in challenging how various normative narratives might work.

gender/TROUBLING, as a video, sculpture and photo-based exhibit, mostly lacked what most performance works have, the actual body in performance. "Merleau-Ponty's conception of 'having a body is that it is a spatial act'" (in Kuppers, 2007, p. 9); for Kuppers this is activated in performative work through the spatial performance of embodiment. Simultaneously, in performance the body exists as image, the body itself, and the ground or context. These positions are mobile. This mobility causes a shift in looking and meaning making, a suspension, a tension, a destabilizing. Theatre director Eugenio Barba ${ }^{1}$ makes use of this technique in his practice. Suspension as physical/mental act is a moment of tension and destabilization and, in holding this moment, both performer and/or audience consider choice and action.

Performance encourages a metaphoric viewing of events, activities, emotions, and ideas - a viewing similar to that required for conceptual or idea-based, art. Petra Kuppers (2007) looks to the performative as a way to play with/in storying and to intermingle object and subject, voice and word. Digital new media and video, video installation, sculpture and photo-based work were then reconfigured in a 
dialogic performative "mash" as exhibition. Multiple voices were raised. The audience entered.

\section{gender/TROUBLING: Activating the For $(u) m$}

The following acts as a somewhat oblique tour of the exhibition, in which I, as curator/viewer, employ looking, invite musing, recall story, and engage in interpretive analysis. My intention here is to connect the performance of the work with viewer response and explicate some of my own and others' learning.

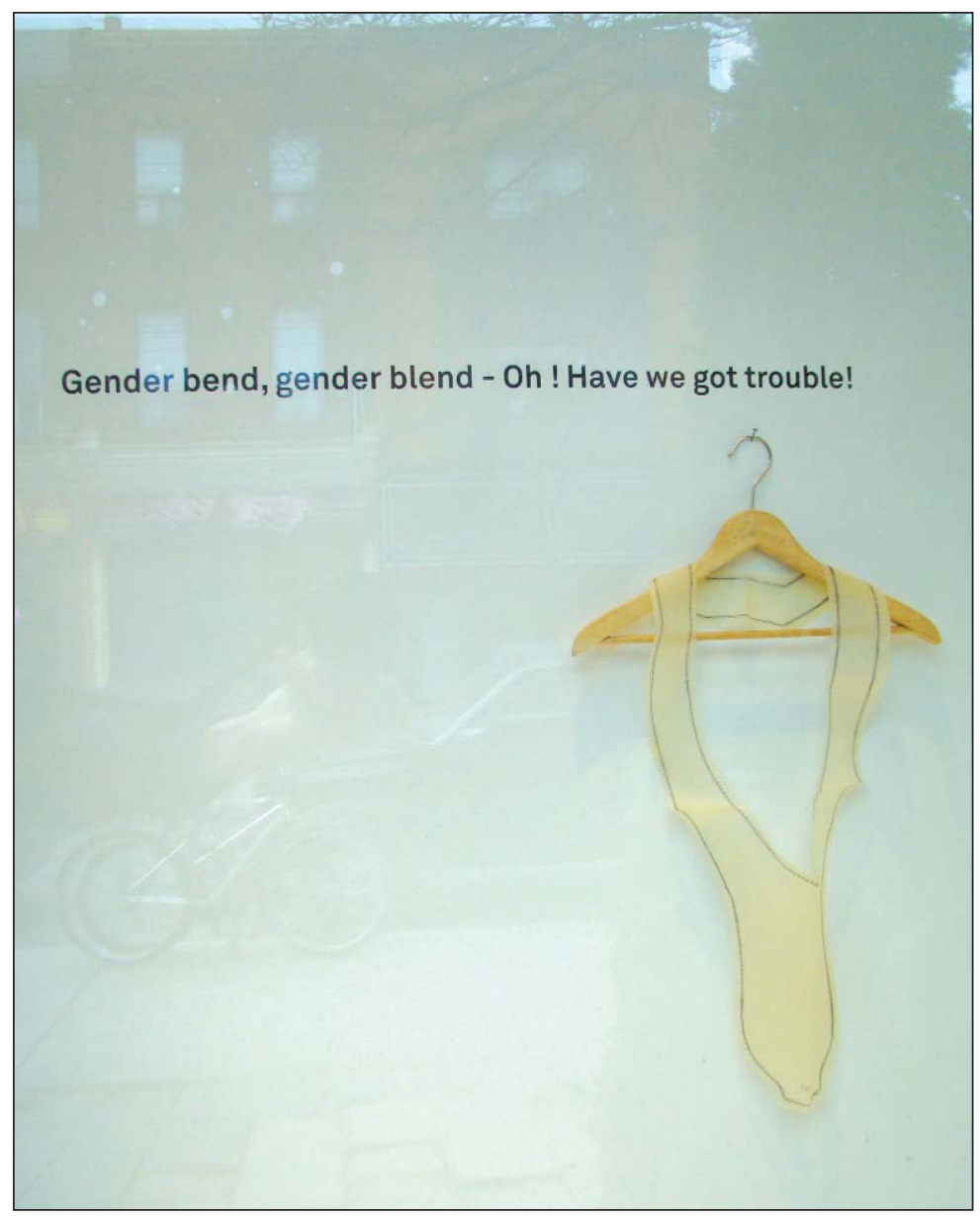

Fig. 1: Gender bend, Gender blend: Oh! Have we got trouble! Questioning gender constraints cannot only cause trouble for us as cultural producers, but also trouble you, the viewer. ${ }^{2}$ 
At the exhibition entrance, a window displays the exhibition title and a tissue paper clothing pattern hung on a metal hanger. This hanging fragment speaks to me of the socially constructed or "patterned" nature of gender-a concept critical to our analysis. A wall panel just inside the door lists the collective participants. I am named as facilitator/curator, assisted by Leena Raudvee and Serena Lee. Cultural producers are video, film, and new media artists Loree Erickson, Spy Dénommé-Welch, Jo SiMalaya Alcampo, and Alexandra Hazisavvas; sculptor Frances Mahon; performance artist Claudia Wittmann; and the activist/artist collective ShiftChange from the AGO Youth Council.

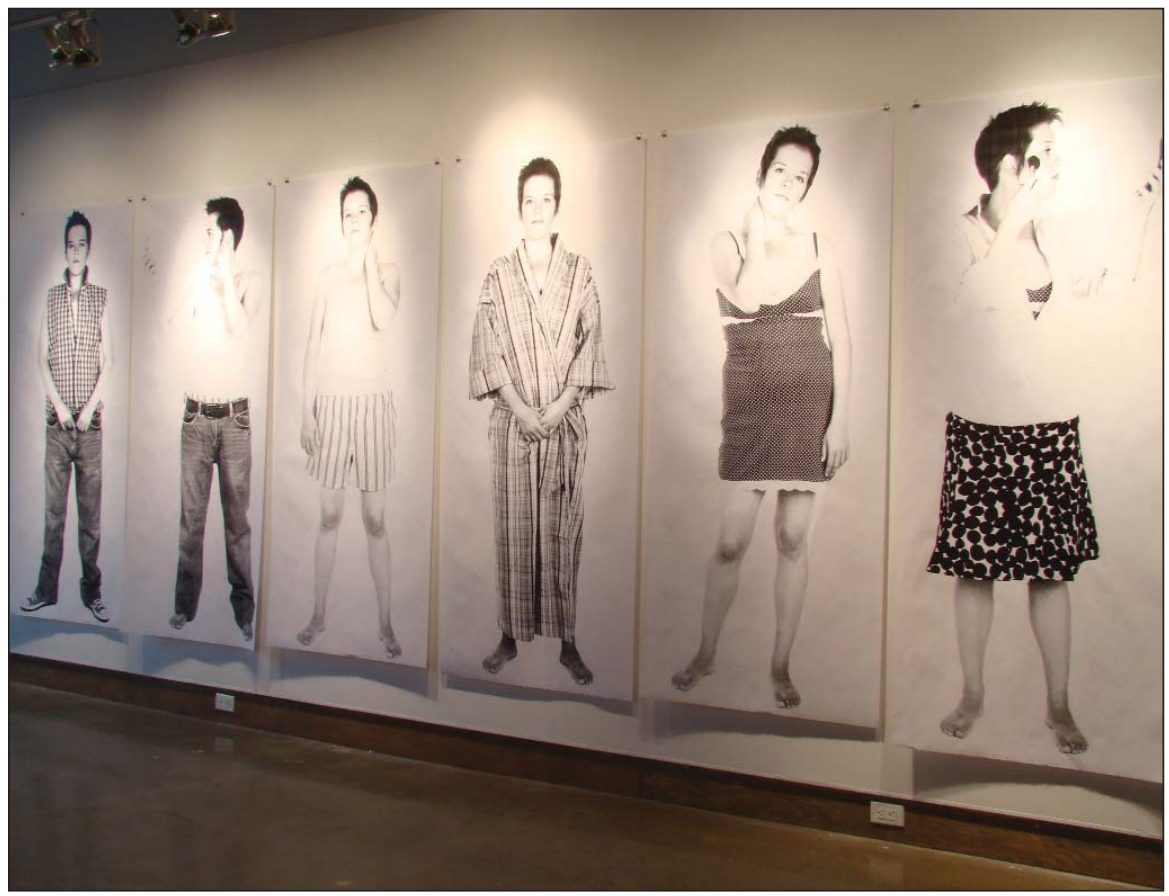

Fig. 2: Gender Super Nova, a life-sized "voguing" or "trying on" of gender by Art Gallery of Ontario Youth Council \& Dan Bergeron, 2008.

ShiftChange's "Gender Super Nova" spreads out along the long wall to the left. The group, gathered together by Syrus Ware, Art Gallery of Ontario Education, explored with visiting artist Dan Bergeron the vagaries experienced in the putting on and taking off of gender as/in a continuum. The life-sized paper photo-based black and white images depict a young person dressed as male transiting through clothing changes to female. The work is both playful and confrontational. The intent is to invite a curious viewing. While an image of someone donning two different costumes does 
not necessarily encourage a complex understanding of gender fluidity, it does, through the use of scale and multiples, open up the potential for performative viewing. It allows viewers, just as does voguing, opportunities for imagining new possibilities. The life-sized photo-based installation becomes the ground wherein the viewers can and did insert themselves.

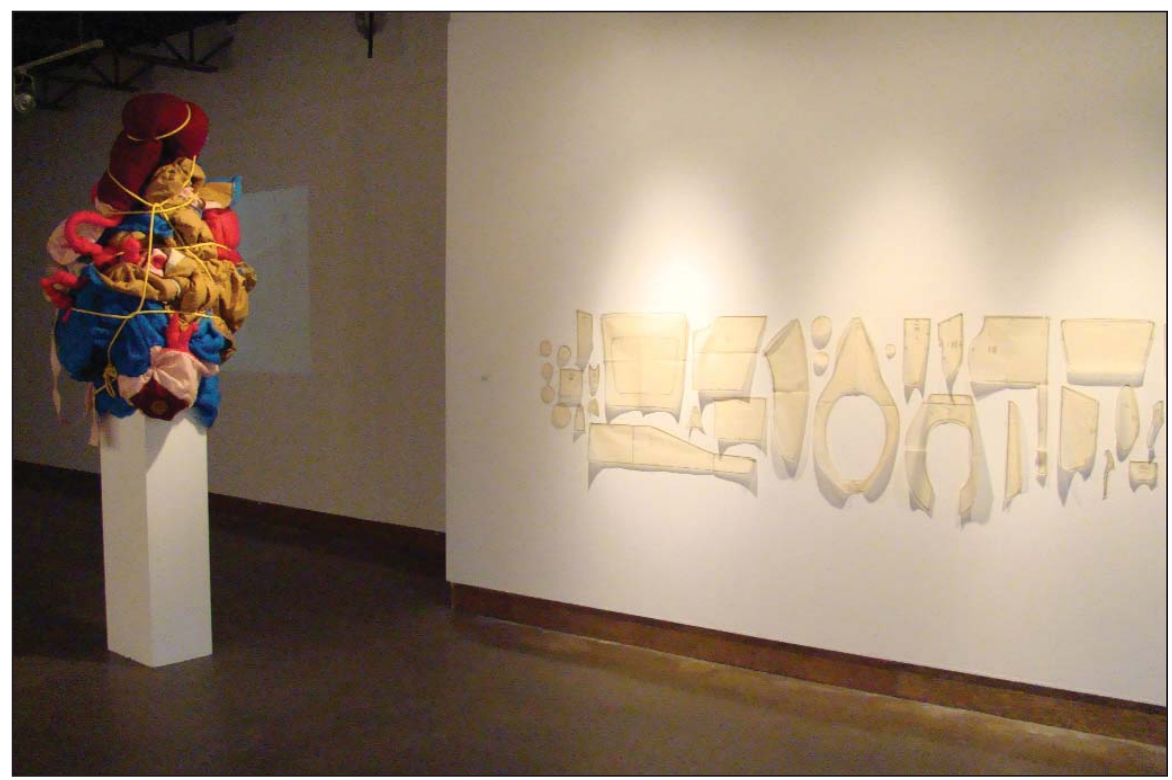

Fig. 3:"Everything is OK Now" is ready for action. The personal (disabled or transgendered) and political (issues of safety and inclusivity) merge in this work.

Frances Mahon's portable do-it-yourself (DIY) fabric-constructed-genderneutral-accessible washroom-as-sculpture titled "Everything is OK Now" is bundled and ready for action. Patterns are pinned to the wall and can be provided on request. She has moved her DIY potty onto college and university campuses lacking such facilities, as protest. The bundled nature of the sculpture makes the washroom form difficult to read. But just as this might be seen as problematic, so too is a "normative" view which does not take into account the issues of transgendered and disabled safety and access. Providing such facilities is sometimes seen as an unnecessary expense for so few and yet how many have used these facilities or taken their children into "disabled" washrooms? But now, suggests Mahon, knowing how useful such a facility is, you can make and tote your own! 


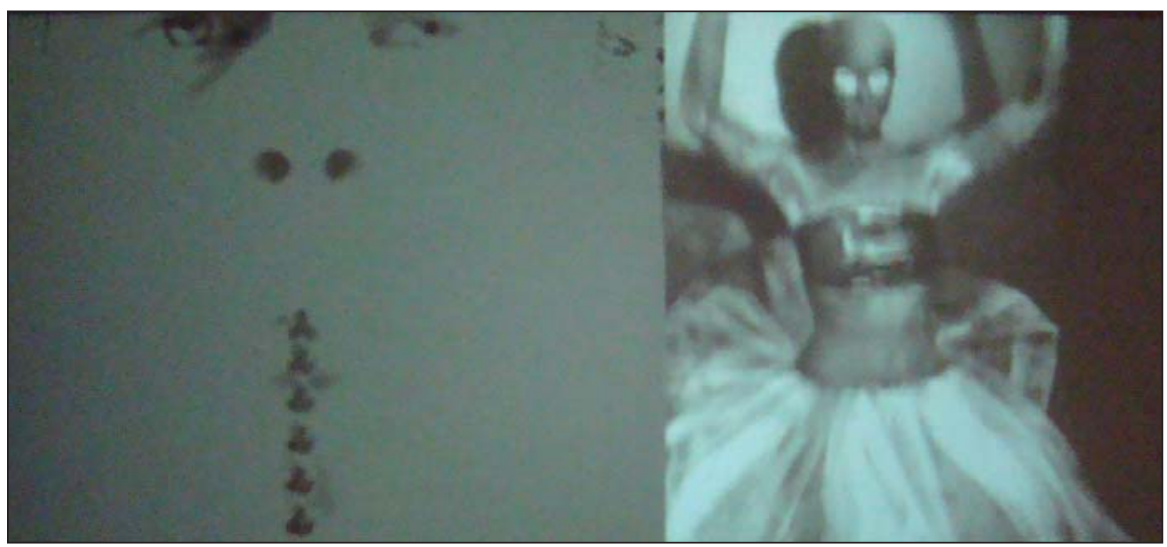

Fig. 4: Blurred and shifting black and white images in Alexandra Hazisavvas' split-screened video installation reference the confluence of gender, race and ethnicity.

Alexandra Hazisavvas' split-screened video projection simultaneously shows, in close-up, a woman swallowing and regurgitating a string of black pearls and a young tutu-clothed woman, alternately blacked and whited out, compressing herself through a pinhole. The juxtaposition of the two video images was critical for the explication of complex meaning. Alexandra had made many non-linear video "stories" and over a period of weeks we looked together at how different juxtapositions and contexts might provide different readings. We felt that this final work would best speak to an internalized mixed-race young woman's struggle. For many viewers, this video installation proved to be one of the most theoretically complex and emotionally compelling pieces.

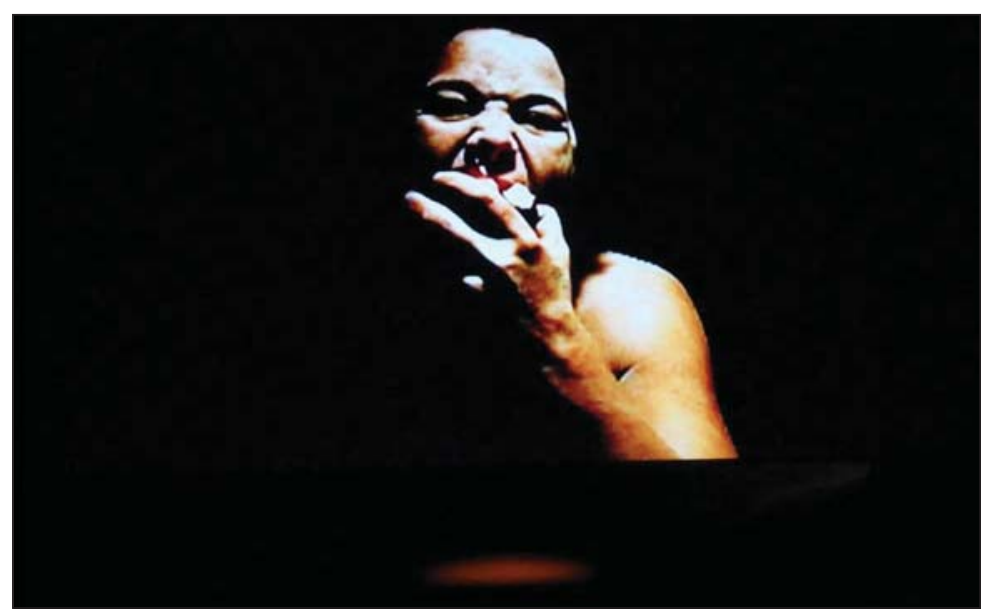

Fig. 5: In XBASE, Alexandra Hazisavvas' video of the "original sin" of gender construction. 
This tension was played out even more dramatically in Alex's video installation in XBASE, XPACE's basement gallery. A video, shown on a monitor placed on an apple-covered plinth, depicts an ambiguously gendered figure who stands in a shower eating an apple. The water turns blood red as it pours over the naked hairstreaked body. The apples, placed on the plinth top in front of the monitor, thematically repeat in "flesh" this painful "eating." As a viewer, I felt drawn to bite into an apple; to enter the work another way. Others drew different, but viscerally similar, interpretive connections to their own "embodied" conflicts.

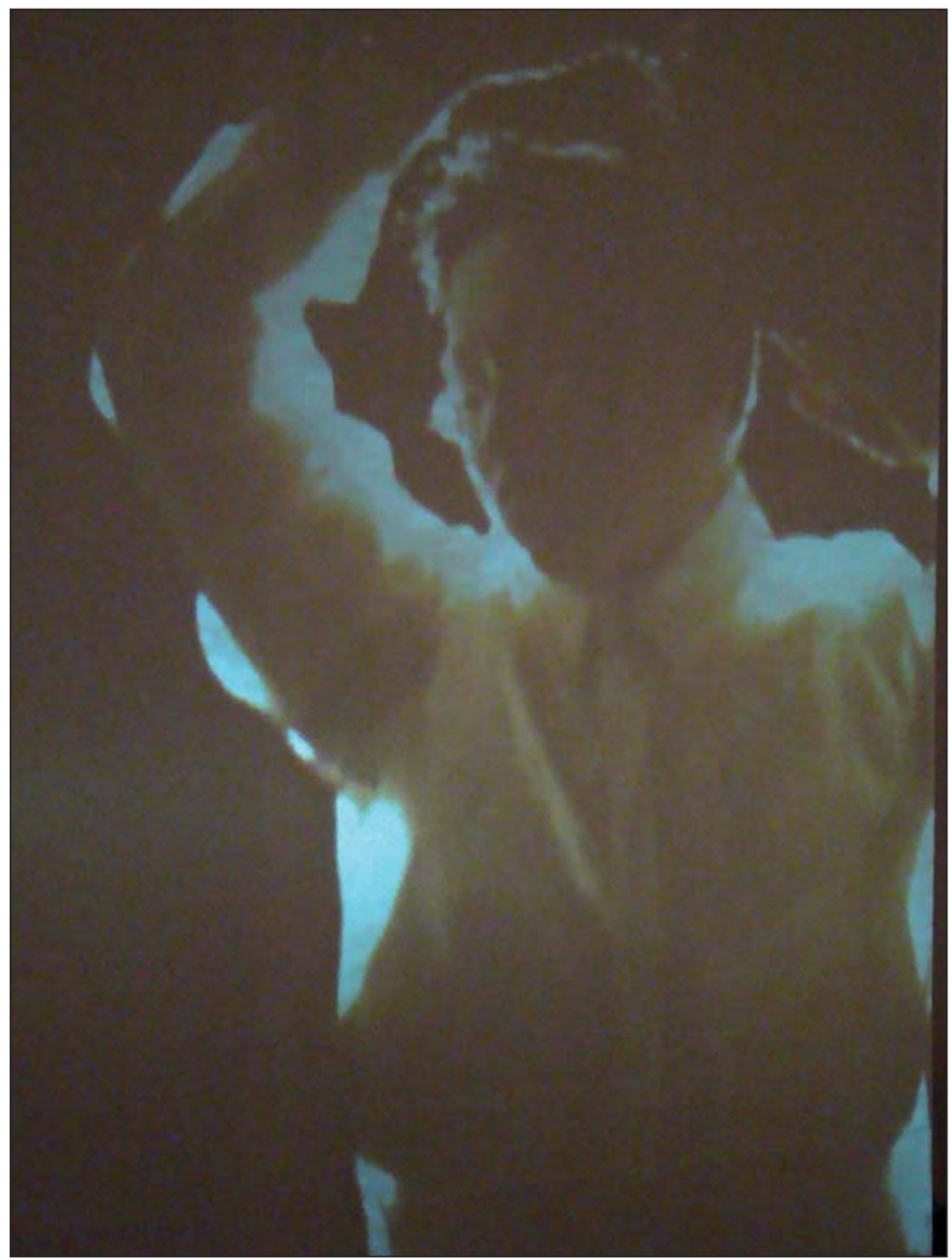

Fig. 6: Jo SiMalaya Alcampo self-projected as fe/male Elvis impersonator-a "cultural" shift. 
Jo SiMalaya Alcampo, self-projected in video onto a translucent fabric surface hanging in the gallery, is dressed in her father's barong, a man's traditional Filipino shirt. She alternately plays with male posturing by crossing her arms in a defiant pose, and with Elvis impersonation as she slicks back her hair with a small black comb. These two images alternate with, and fold into, each other. They operate as indistinct forms, barely visible. Jo had spoken to the group earlier about her ideas around the visibility and strictures of gender, how it is so labeled and delineated in the west, where transgressions from traditional binary expectations can be treated with severity. In The Philippines, just as Jo's images float and shift, barely visible in the gallery, so does gender glide beneath society's regulatory radar. It is understood as more fluid, and hence invites, rather than restricts, play.

Both Loree Erickson and Spy Dénommé-Welch introduce further gender complexity in their autobiographical films: Loree as a self-declared femmegimp porn star, and Spy as two-spirited or transgendered aboriginal. Advertised as an evening presentation, discussion, and reception, five videos (two of Loree's and three of Spy's) are screened. Loree's videos "Sexxy" and "Want" play with gender, disability, and sexuality. Images and story invite us to share in the intimacies of a personal care team, the pleasure of a sexual encounter, and the sexiness of wheelchairs, as well as how Loree negotiates a harsh, uncomprehending and unaccommodating world. The work is both sensitive and provocative.

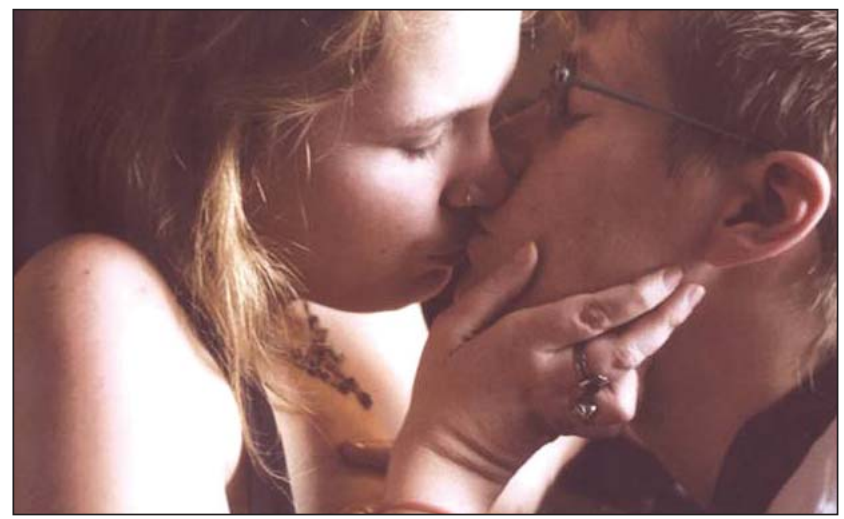

Fig.7: Self-declared femmegimp porn star, Loree Erickson wants it all and finds it in life, love and the "sexiness" of wheelchairs. 
Spy's "The Making of a Hybrid Male" is a humorous and poignant comingout story of a young Trans "man." Spy, his life companion Catherine, and their two dogs drive from a large urban centre through a changing landscape to the north. Over the journey, conversations with Catherine and emerging fantasies and inner dialogue anticipate the impending meeting with Spy's elders. The video speaks to transiting cultures, spaces, and bodies. His two animated video shorts, "Naming/Claiming: A Brief Journey through Memory Space" and "Contact/Border: A Brief Lesson in History," expose the erasure of aboriginal people, land, and culture: forests and people are scribbled into oblivion, a city landscape erupts and despoils the forest, lights blanket and mark, as disease, the earth. In showing the animated works juxtaposed with “Hybrid Male," Spy generates new questions at the confluence of gender, culture, and history.

While many of Spy's and Loree's videos operated, as did much of the work in the exhibition, as more evocative than narrative, both "The Making of a Hybrid Male" and "Want" are told in story form and provided easier access for the audience to the artists' challenges, needs, and desires. Shown at the opening of the exhibit, they served to initiate discussion and provided a useful context with which the audience could make critical connections for entering other works.

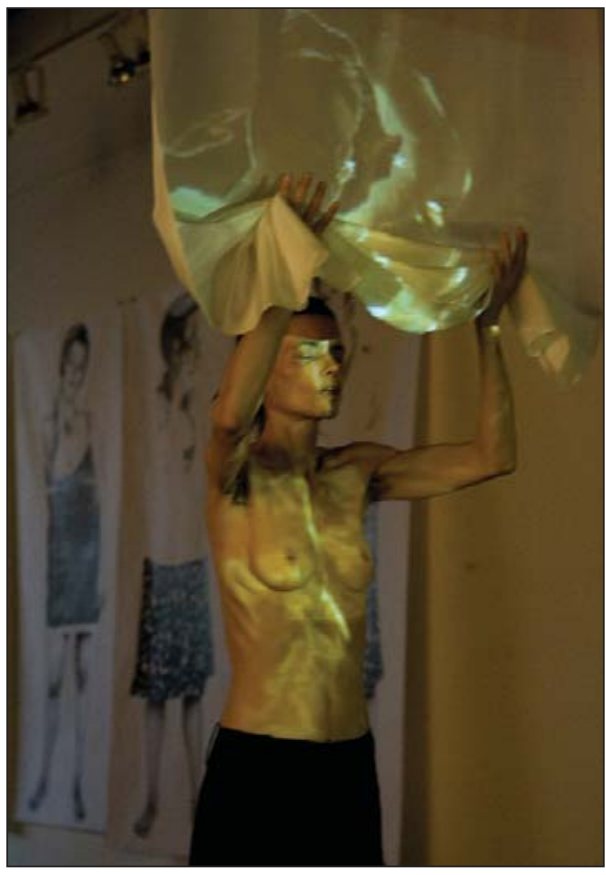

Fig. 8: Claudia Wittmann "performs," à la Grotowski, her own gender research in "conversation" with Jo SiMalay Alcampo's work. 
Performance artist Claudia Wittmann, after improvising alone each night during the exhibition week with all the works in the gallery, presents a performance on the final Sunday in response to Jo Alcampo's video installation. Claudia questions whether one can actually get to a place physically and psychically beyond or before gender. Trained in the sciences as a researcher, and in performance as a Butoh performer and Grotowski actor, she brings an honesty and intensity-in gesture and emotion-to her performance.

This presentation was followed, as has been much of our work together and with our audiences, with a discussion.

\section{The Discussions: Learning as Pedagogy}

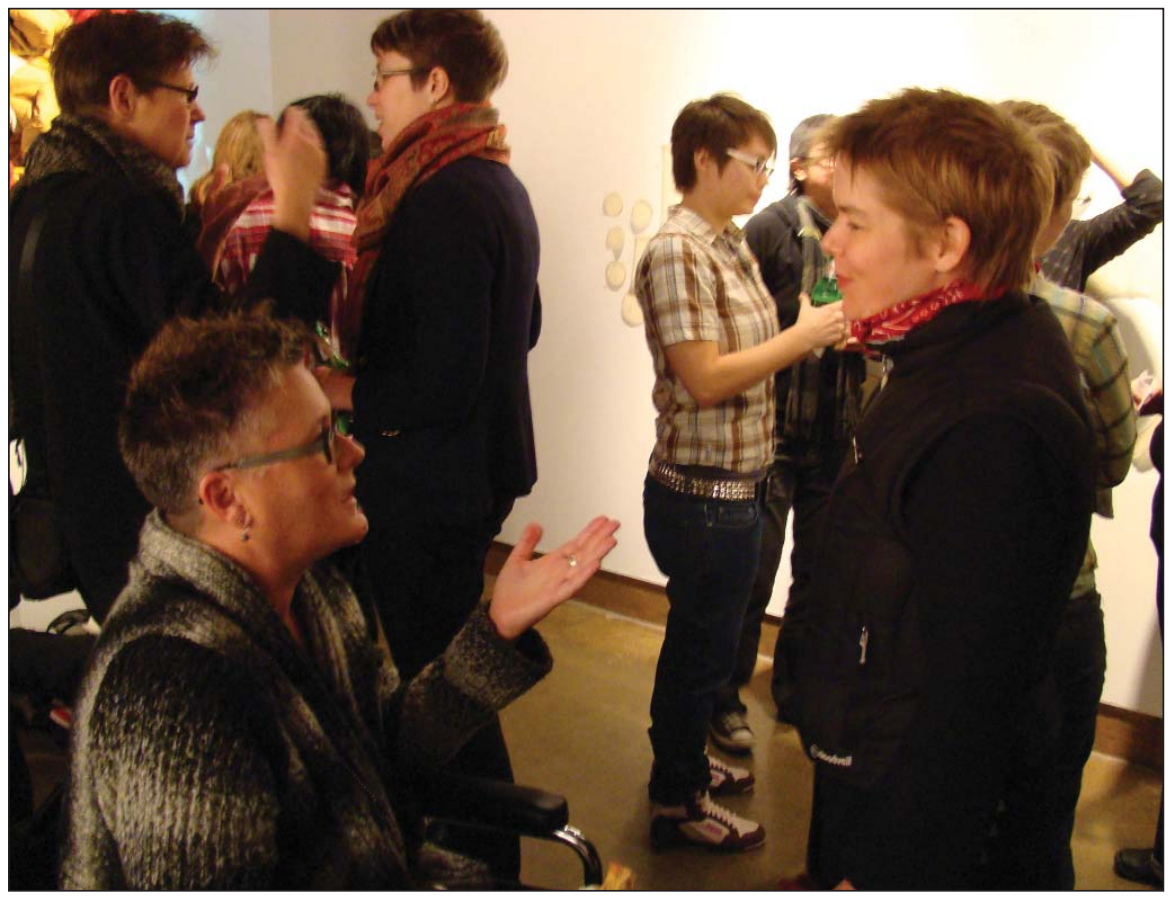

Fig. 9: Following the screening of the videos at the "gender/TROUBLING" opening was our first public discussion (author/curator is in the wheelchair at left). 
The public response was overwhelming and positive. The space created by the exhibition accommodated and welcomed the programmed receptions, screenings, and discussions and encouraged informal meetings, talks, and visits by school groups. Our audience was eclectic and included: Ontario College of Art and Design University students and faculty, members of downtown Toronto art, social, and academic communities, teens from the Art Gallery of Ontario Youth Council and Toronto School of Art, students from alternative secondary schools, and family and friends. In each performative moment reflection was a crucial complement. Discussion was key. One school group, from a Toronto alternative school, came to see the show responding to one student's urgent need to challenge our use of derogatory works in the exhibition advertising. Serena, Jo and I met with the group and the discussion centered on words, the power of words, how we can reclaim words and re-perform them in new contexts to empower ourselves. We agreed that such words act as performative "utterances" ... wherein the power of the theatrical makes the imaginative "flesh" (Schechner, 2006, p. 124).

The discussions both within the group and with the public were significant not only for their content and process (i.e., instrumental in contextualizing the work, in building collective understandings and empathy, and in generating and receiving public reaction and response), but also by how they were defined. It was refreshing for many to be able to talk in a space so characterized by diversity, inclusion, and gender complexity.

Most of the discussions were videotaped or informally recorded in journal writings, emails, blog and Facebook posts by me, project participants and by those who attended the public sessions. Further dissemination, discussion and reframing of this "data" still continue through various sites and projects both private and public.

Our stories were what initially engaged us. The intent eventually became to find a way to interconnect these and use them to "draw" visual maps representative of the complexity of our lives. A curious questioning framed our project sessions and this, as learning practice, became transposed onto the public talks. The project discussions provided a fertile ground for developing content, form, and inspiration, and the public talks for further questioning, critique, and idea expansion. Claudia's performance gave physical form to the nature of these exchanges. 


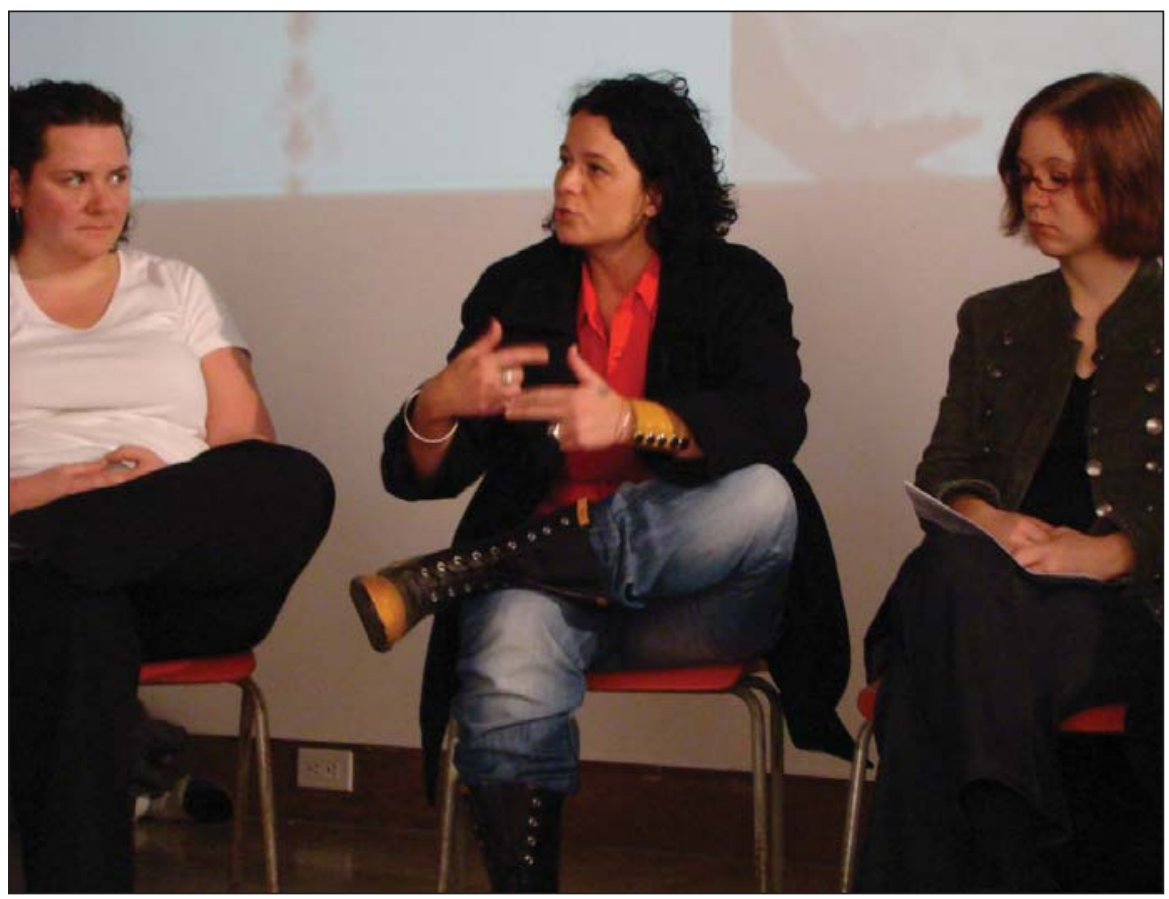

Fig. 10: A Friday afternoon public discussion with Alexandra Hazisavvas (centre). To Alex's left is Catherine Magowan from "An Ind(i)en Rights Reserve," a multi-arts production company.

Discussion issues raised were varied. For example, Loree spoke about how her films tended to be screened in either disability festivals or queer festivals. In the former, the explicit sexual scenes were seen as problematic, and in the latter, disability became invisible. Neither venue was especially comfortable with the presentation of a complex gender fluidity.

Perhaps one might assume that the content of this exhibition and its surrounding events and discussions were overly reliant on the odd, the exotic, or impaired, but in fact this was not the case. The exhibit created an atmosphere of heady inclusivity. It invited all-hetero, white, brown, bi, male, able-bodied and disabled-to shift paradigms.

This shift suggests a viewing different from one so defined and constrained by the "normal" Western binary. Viewers were asked to accept a more complex and diverse understanding of gender for individuals and communities. Inclusion then is not predicated on making room for the different or marginalized, but rather on rethinking a society in which environment, personal attitudes and perceptions, and 
institutional organization are flexible and welcoming. We become raced, gendered and disabled not because of individual difference, but rather a result of social construction and designation.

This paradigm shift was for me and many participants the key learning in this work. In letting go of categories and definition - the tyranny of labeling - I felt myself enter into a queasy unfamiliar space. The experience was much like being in a foreign country where one does not speak the language. Julia Kristeva (1991) writes in "Strangers to Ourselves," "Being alienated from myself, as painful as that may be, provides me with that exquisite distance within which perverse pleasure begins, as well as the possibility of my imagining and thinking, the impetus of my culture" (pp. 13-14).

Audience learning varied. One might expect that not many would be willing to give up the conventions of normalcy, especially if they had been serving them well. But as a former student of mine asked on preparing an exhibit and talk, "The Violence of Gender Norms," "Does labeling, in the long run, really do anyone any good?" The younger crowd, especially the art students, was generally very open, willing to be playful and curious. While the impact was not as so profound for all, we were told we created a safe, enjoyable, challenging, and inclusive space in the gallery.

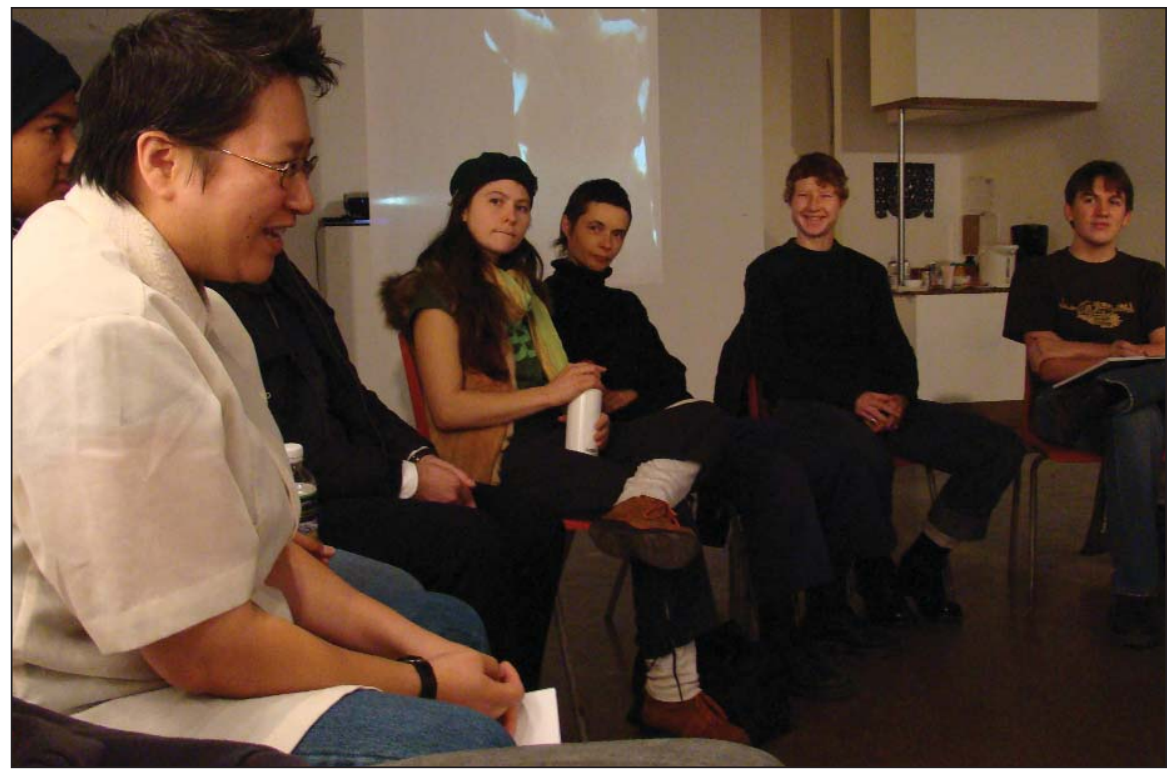

Fig. 11: A public discussion on the final day with the project group. Some participants are perplexed while others experience a heady joy. (Jo SiMalaya Alcampo is seated on the left). 
Good learning invites many interpretations. It is open and evolving. When we return day after day to our learning, we receive differing interpretations and understandings of what we do and what we know over time. These shifts keep us moving, ever active, ever questioning. This invites a way of being in learning which is open to ambiguity and to change.

This perception provided the rationale for inviting gender/TROUBLING participants and viewers to live in the uncomfortable place of unpredictability. It reminded us of the fact that often there is no one answer. It encouraged us to risk shaping various forms. The for"ums" became pauses, breaths, changes-forms to observe, moments to hear, opportunities to reflect-which allowed us to generate various texts to mark and give meaning to our progress.

In making art of our bodies, we intentionally placed our bodies in the world. In doing so, we energized a site between meaning and creation, audience and artist. Using body-as-template, we created complex images of gender, race, and disability in public space and in so doing affirmed the importance of such images, practices and ideas in rendering the suppressed visible. We were heartened to see, as does feminist cultural theorist, Janet Wolff (2003), that some leakage into the culture in general from occasions such as these were possible.

\section{Closing}

gender/TROUBLING has spawned further projects which I have shared in as viewer and/or as sounding board. Project artists Claudia Wittmann and Jo SiMalaya Alcampo continue to work with these ideas: Claudia performs, facilitates workshops, and presents on gender construction, and Jo empowers herself and others using story to elucidate her cultural heritage and ongoing formation in her new media installations. In closing, I share a recent writing sent to me by Jo as she prepared to mount a new exhibition:

This past year I visited the Philippines to conduct research and visit my family. Some of the best times were when we would gather at the same dining table, my father and his siblings had gathered around as children and I would listen to our family stories unfold. My Ninang (Godmother) said that she could hear the voices of her mother and father at those times because those who have passed on are present when we include them in the telling. 
I believe that we can inherit the emotions of these stories across generations. While these reconnections across time bring me the joy of a deeper understanding of the story of my family and homeland, they also bring an unresolved sadness and a longing to make meaning from traumatic history. (Alcampo, personal communication, May 6, 2010)

Perhaps we can engage with different stories, playing and learning collectively, drawing connections across generations and cultures. Lita Fontaine (2009), an aboriginal feminist artist and activist from Winnipeg, spoke in conversation to this process. She suggested that we should not force parallels but use them, build bridges rather than define further separation. Do we need to reeducate each other in entirely new vocabularies and problems? Let us work collectively in the spaces between and activate our different contexts, narratives, and relationships to comprehend and illuminate. Let us employ multiple strategies to analyze how our stories operate to reveal conscious experiences and reflect social landscapes, and use them creatively in our art. While these analyses exist in relationship, sometimes in tension with one another, taken collectively, they suggest different ways of thinking of, and being with, our complex, ever-learning, selves.

\section{Notes}

1. I had the opportunity to train with Odin Theatre Director Eugenio Barba when was he was in Toronto in the early 1980s. We continued to correspond for years after, discussing direction and drama theory. His books such as "The Floating Islands" (1986, New York: PAJ) also record his training theory, and performances. This comment is excerpted from my notes on my training with him.

2. Photography credits: Figures 1-6, 8-11: John Oughton with thanks to the artists and XPACE Cultural Centre. Figure 7: Provided by, and thanks to, Loree Erickson. 


\section{References}

Butler, J. (1988). Performative acts and gender constitution: An essay in phenomenology and feminist theory, Theatre Journal, 40(4), 519-531.

Fontaine, L. (2009). Adapted from a conversation we had at Plug In Institute for Contemporary Art Residency, Summer 2009.

Garoian, C. (1999). Performing pedagogy: Toward an art of politics. Albany: State University of New York.

Gray, R, Sinding, C., Ivonoffski, V., Fitch, M., Hampson, A., \& Greenberg, M. (2000). The use of research-based theatre in a project related to metastatic breast cancer. Health Expectations, 3, 137-144.

Kristeva, J. (1991). Toccata and fugue for the foreigner. In J. Kristeva, Strangers to ourselves (pp. 1-40). New York: Columbia University Press.

Kuppers, P. (2003). Disability and contemporary performance: Bodies on edge. New York: Routledge.

Kuppers, P. (2007). The Scar of visibility: Medical performances and contemporary art. Minneapolis: University of Minnesota Press.

Lugones, M. (1990). Playfulness, "world" - travelling, and loving perception. In Gloria Anzaldua (ed.) Making face, making soul: Hacienda caras (pp. 390-402). San Francisco: Ann Lute Books.
Paget, M. (1990). Performing the text. Journal of Contemporary Ethnography, 19(1), 136-155.

Patterson, P. (2006). Pause and play: Is this the "um" in Curriculum? A performance artist acts out in the academy (keynote), Collisions 2006, University of Victoria.

Personal Narratives Group (1989). (Ed.). Interpreting women's lives: Feminist theory and personal narratives. Bloomington: Indiana University.

Piper, A. (1996). Out of order, Out of sight. Volume 1: Selected writings in meta-art, 1968-1992. Cambridge, MA: MIT Press.

Schechner, R. (2006). Performance studies: An introduction $2^{\text {nd }}$ edition. New York: Routledge.

Szent-Gyorgyi, A. (date unknown). FamousQuotes.com. Retrieved May 2, 2011, from http://www.famousquotes.com/author/al bert-szent-gyorgyi/

Wolff, H. (2007). (Trans. Nicholas Grindell). The Tears of photography, Grey Room, 29 Fall, 66-89, Massachusetts Institute of Technology.

Wolff, J. (2003). Reinstating corporeality: Feminism and body politics. In A. Jones (Ed.), The Feminism and Culture Reader (pp. 414-425). London: Routledge. 


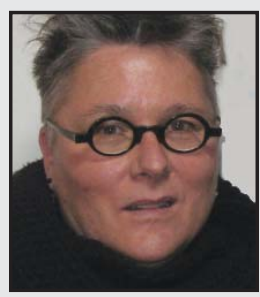

Pam Patterson's (PhD) research, performance and teaching have focused on disability and gender, performativity, and trans-praxis as process. She is an Associate Scholar and Director for the interdisciplinary arts program WIA projects for the CWSE, OISE/UT, and teaches at the Ontario College of Art and Design University. As a performance and visual artist she was a founding member of FADO Performance and ARTIFACTS and has exhibited and performed internationally.

LINK TO:

www.wiaprojects.com

http://pampatterson-performanceartist.blogspot.com/ 